
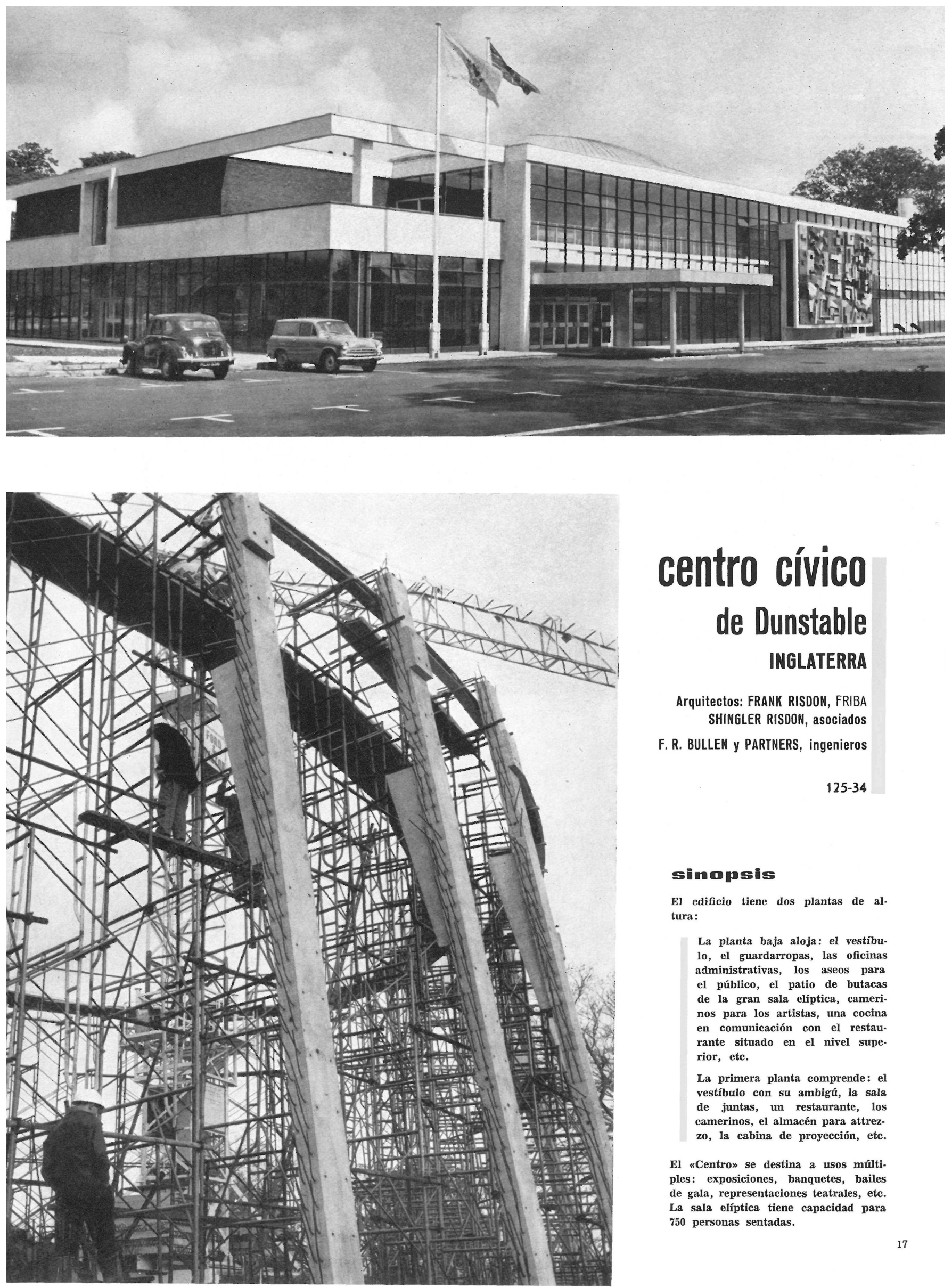

\section{centro cívico}

\section{de Dunstable \\ INGLATERRA}

Arquitectos: FRANK RISDON, FRIBA

SHINGLER RISDON, asociados

F. R. BULLEN y PARTNERS, ingenieros

$125-34$

\section{simopsis}

El edificio tiene dos plantas de altura:

La planta baja aloja: el vestíbulo, el guardarropas, las oficinas administrativas, los aseos para el público, el patio de butacas de la gran sala elíptica, camerinos para los artistas, una cocina en comunicación con el restaurante situado en el nivel superior, etc.

La primera planta comprende: el vestíbulo con su ambigú, la sala de juntas, un restaurante, los camerinos, el almacén para attrezzo, la cabina de proyección, etc.

El «Centro» se destina a usos múlti. ples: exposiciones, banquetes, bailes de gala, representaciones teatrales, etc. La sala elíptica tiene capacidad para 750 personas sentadas. 


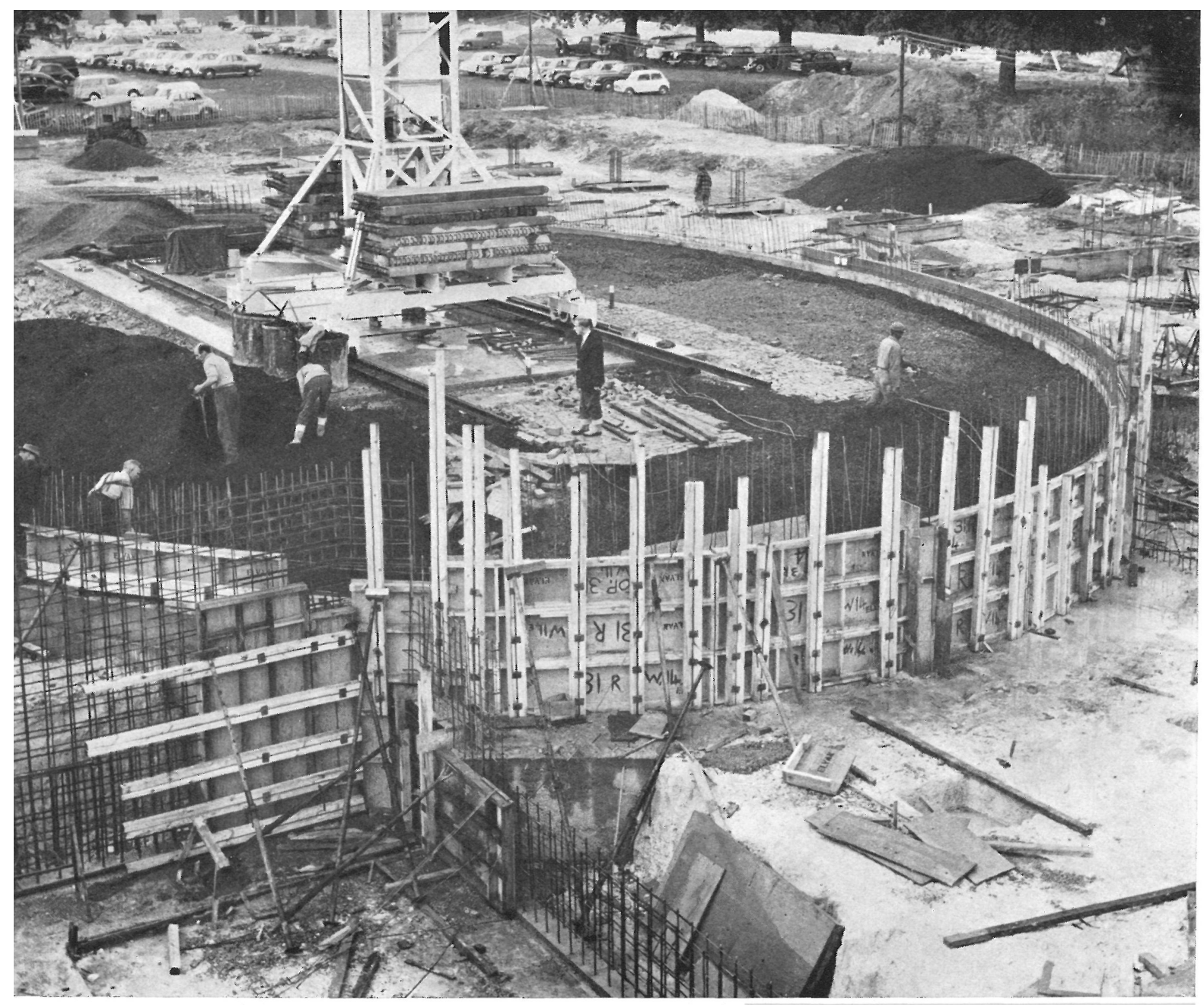

El edificio ha sido proyectado y construido para servir a múltiples usos: conciertos sinfónicos, bailes de gala, banquetes, exposiciones, representaciones teatrales y cinematográficas, combates de lucha libre, etc.

El elemento principal está constituido por la gran sala elíptica — con capacidad para 750 asientos-, coronada por una cúpula, cubierta de aluminio, que destaca limpiamente sobre las superficies de hormigón traslúcido que cubren los «foyers» y otras salas auxiliares.

Entre estas últimas figura la Sala Vernon -con capacidad para 110 personas, utilizada actualmente como sala de juntas del Consejo- y un restaurante, situados ambos en la primera planta. Dicho restaurante es servido desde una cocina — situada en la planta baja-, la cual tiene comunicación directa con la sala elíptica y está adecuadamente equipada para servir a ésta en los casos en que sea empleada para la celebración de banquetes.
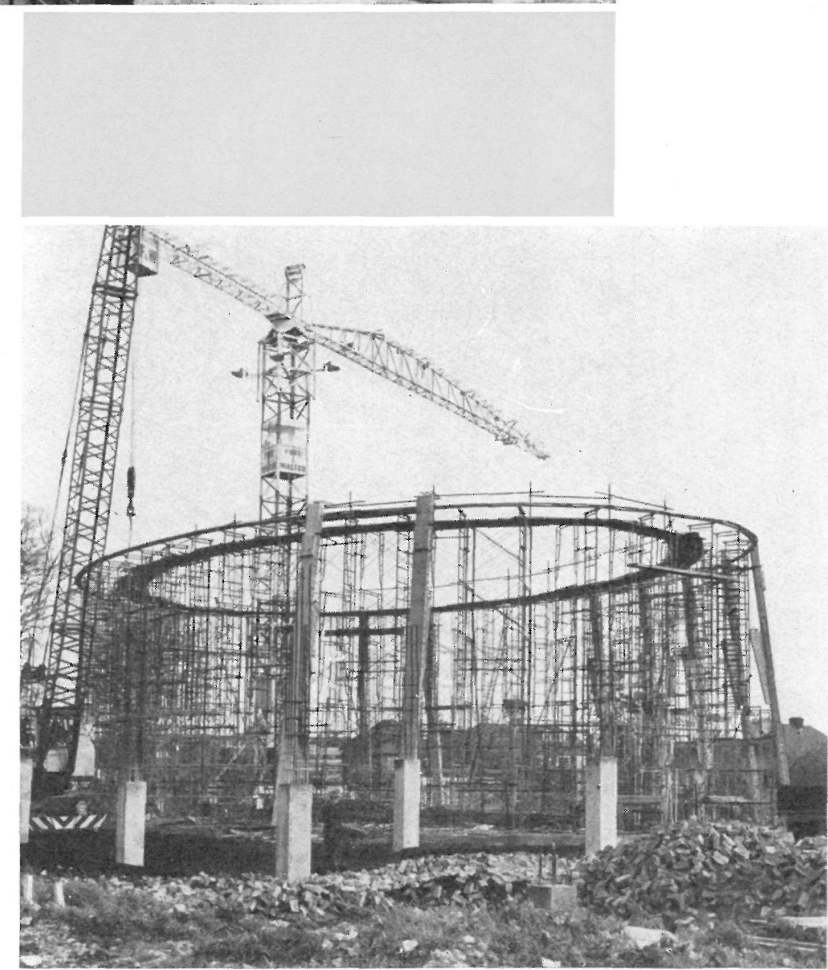


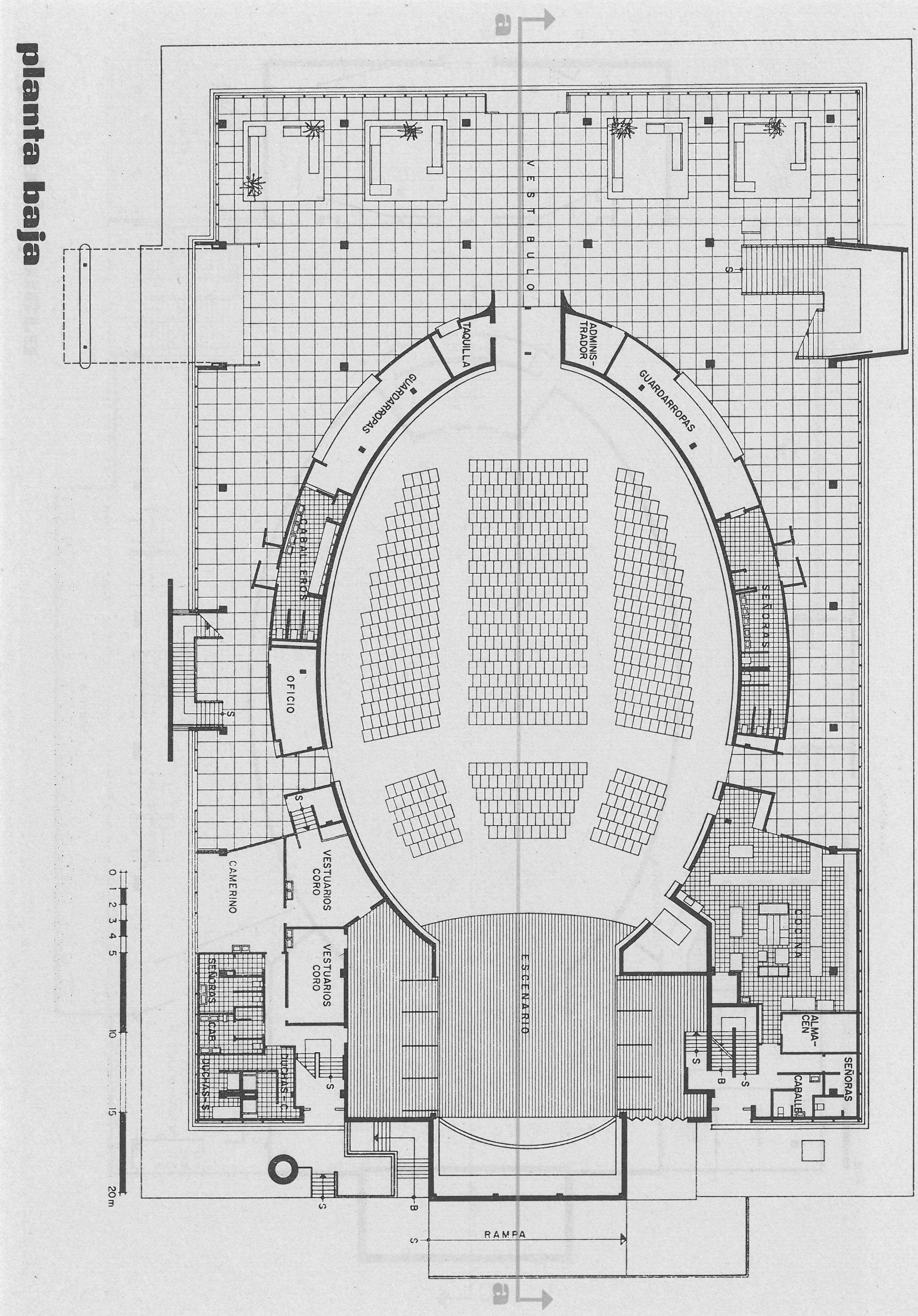




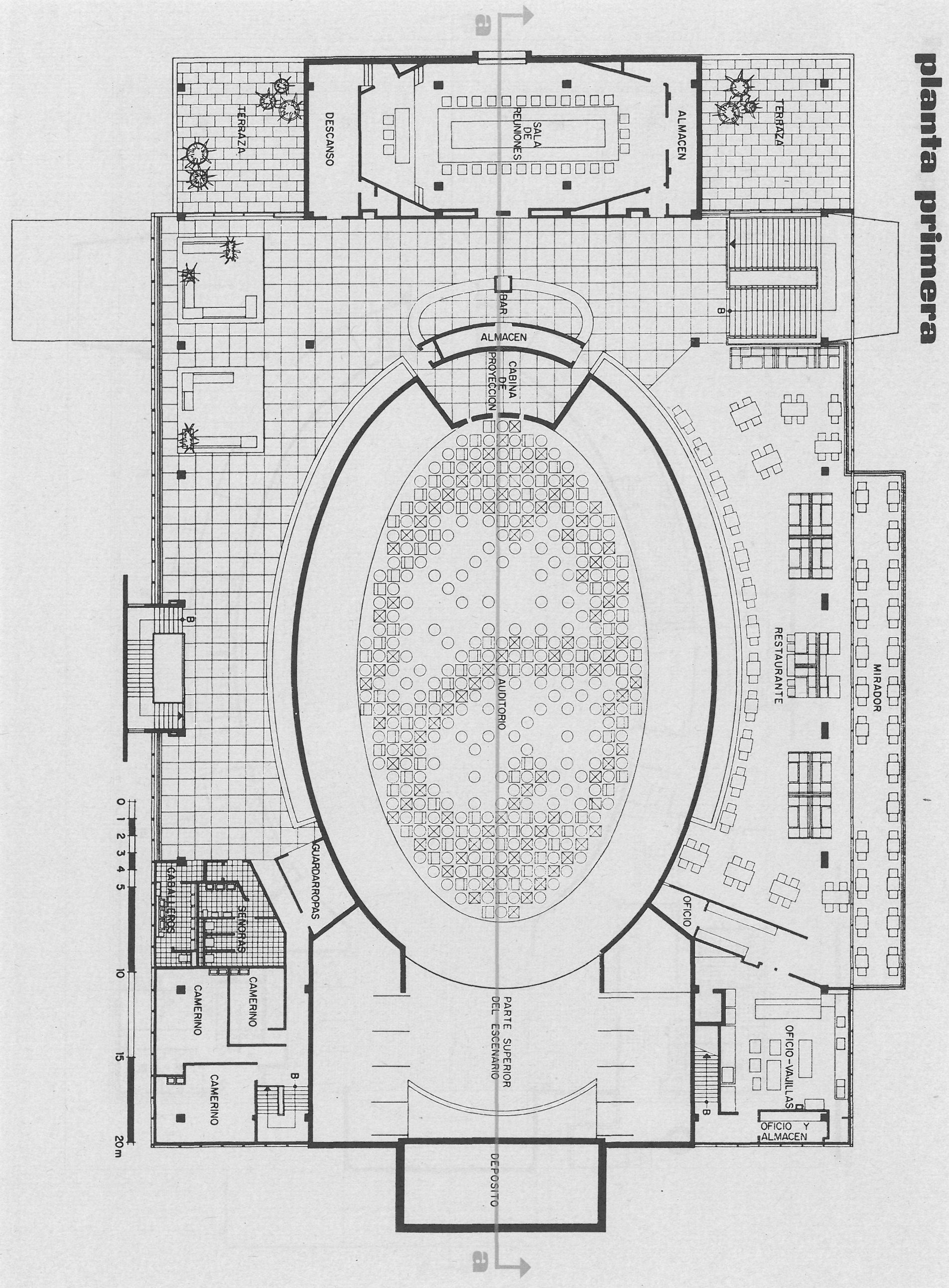




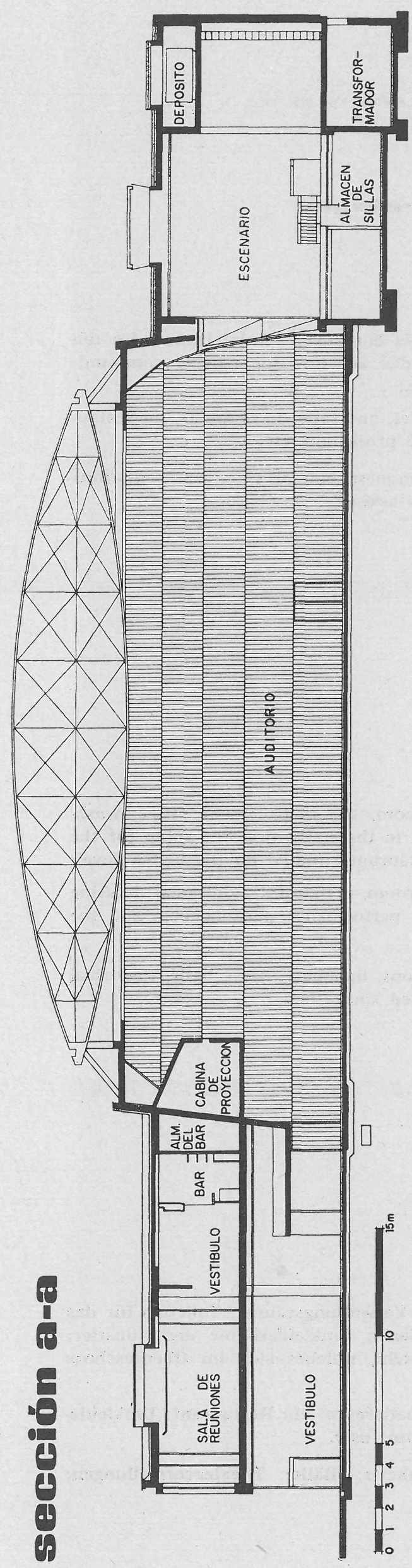

Paralelo al anillo elíptico que envuelve la mencionada sala, y en contacto con el gran "foyer» de la planta baja, ha sido construido un núcleo con los servicios generales para el público: guardarropas, oficinas administrativas, taquilla, aseos, etc.; destinándose las zonas situadas al lado del escenario para alojar los camerinos de los artistas, almacenes para el attrezzo, etcétera.

La estructura principal del edificio es de hormigón armado con un cuerpo central, en forma de tronco de cono, de sección elíptica, que encierra la gran sala y actúa como soporte de la primera planta y de la cubierta.

El auditorio está cubierto por cerchas metálicas que se apoyan sobre un anillo de borde de hormigón, anclándose lateralmente a los soportes inclinados, asimismo de hormigón; como elemento de cobertura se ha colocado una lámina de aluminio.

En los cerramientos exteriores del edificio ha sido preferentemente utilizado el muro cortina.

Realza la composición de la fachada a la plaza principal, al nivel de la primera planta, el recercado de la ventana de la Sala Vernon, construido en mármol blanco, que actúa ópticamente como eslabón de conexión con las nuevas oficinas municipales.

En la fachada nordeste se acusa la caja de la escalera principal.

Interiormente el auditorio está revestido, desde el nivel del patio de butacas hasta las ventanas situadas inmediatamente debajo de la cúpula, con paneles verticales destinados a lograr el adecuado aislamiento acústico. El intradós de la cúpula está constituido por un cielorraso suspendido, a base de yeso y materiales fibrosos, ricamente moldurado y cuidadosamente estudiado para dotarlo de óptimas propiedades decorativas y acústicas. El pavimento es de madera; y cuando no es utilizado para la celebración de bailes, se le protege mediante alfombras.

En el extremo más estrecho del recinto elíptico, opuesto a la entrada, hay un escenario móvil, que se utiliza para representaciones teatrales y está dotado y equipado con todos los elementos que proporciona la técnica moderna.

Los paramentos interiores de la sala de juntas van revestidos con mármol blanco y aluminio; el cielorraso suspendido ha sido construido a base de placas acústicas, las cuales dejan en la parte central un lucernario que permite el paso de la luz a través de una superficie traslúcida. 


\section{Centre civique di Dunstable - Grande-Bretagne}

Architectes: Frank Risdon, FRIBA. Shingler Risdon, associés

F. R. Bullen and Partners, ingénieurs

Cet édifice comprend deux niveaux:

- le rez-de-chaussée comprend le vestibule, le vestiaire, les bureaux d'administration, les toilettes publiques, la grande salle elliptique, les loges des artistes, une cuisine communiquant avec le restaurant situé au niveau supérieur, etc.;

- le premier étage est occupé par un vestibule avec buffet, une salle de réunions, un restaurant, des loges, un magasin de costumes, une cabine de projection, etc.

Le centre est destiné à plusieurs manifestations: expositions, banquets, bals de gala, représentations theâtrales, etc. La salle elliptique peut accueillir 750 personnes assises.

\section{Bivic cemtre cat Dumstable - Britain}

Architects: Frank Risdon, FRIBA. Shingler Risdon, associates

F. R. Bullen and Partners, engineers

This civic centre has two storeys:

- The ground floor provides room for a vestibule, cloakroom, the management office, washroom for the public, the large elliptic hall and access to the stalls, dressing room for the actors, and a kitchen in communication with the restaurant situated on the higher level;

- The second storey comprises a hall and bar, council room, restaurant, additional dressing rooms for actors, storage room for dresses and other performance paraphenelia, and the room for the cinematographic projectors.

This civic centre has many useful functions, such as exhibitions, banquets, dress balls, theatrical performances, etc. The elliptical hall accommodates 750 seated spectators.

\section{Fosthalle in Dumstruble - England}

Architekten: Frank Risdon, FRIBA. Shingler Risdon, Mitarbeiter

F. R. Bullen and Partners, Ingenieure

Das Gebäude ist zweigeschossig:

- Das Erdgeschoss umfasst: Eingangshalle; Garderoben; Verwaltungsräume; Toiletten für das Publikum; Zuschauerraum des grossen elliptischen Saals; Umkleideråume der Künstler; eine Küche, die mit dem Restaurant in Verbindung steht, welches sich im Obergeschoss befindet; usw.

- Das Obergeschoss umfasst: Halle mit Büffet; Aufenthaltsraum; ein Restaurant; Umkleidekabinen; Lager für Kostüme und Kulissen; Vorführraum; usw.

Das «Zentrum» dient vielfältigen Zwecken: Ausstellungen; Banketts; Bälle; Theatervorstellungen; usw. Der elliptische Saal fasst 750 Sitzplätze. 